Language Perception in the East Midlands in England

NATALIE BRABER

Investigating East Midlands adolescents' perception of language variation in the UK

\title{
Introduction
}

Previous research by the author has examined the concept of identity in the East Midlands and how this can be relatively problematic in the region (Braber, 2014). This paper aims to extend this topic by investigating views of young people living in the East Midlands using a folk linguistic approach. Preston $(1989,1999 b)$ claims that perceptual dialectology looks at non-linguists' beliefs and perceptions about the similarities of their own speech to, and differences from, the speech of others. This involves examining where participants believe dialect areas to be and what the characteristics of local speech are. This paper examines dialect identification and investigates the abilities of a sample group of adolescents to place correctly local and regional varieties of English.

Preston states that attitudes towards languages are tied to attitudes towards groups of speakers but that much of this research does not consider where respondents think accents are from and whether they can correctly place accents (Clopper and Pisoni, 2004: 114; Preston, 1989: 3-4; Preston, 2002: 51). Past research has frequently presumed that people are accurate at recognising local dialect varieties (Williams, Garrett \& Coupland, 1999: 345). Preston has found that non-linguists were accurate at allocating nine speakers on a north-south scale in the US (Preston, 1996b) and a study carried out by Williams et al. (1999) has established that Welsh teenagers were accurate at perceiving voices from their own location. This study aims to examine this from an East Midlands perspective and shows that these adolescents were not accurate at recognising local accents. Previous studies have examined perception attitudes with questionnaire data, draw-a-map tasks (including placing arrows; drawing boundaries on maps; examining where people are thought to speak differently) and dialect identification (different examples of such studies can be found in the two volumes of The Handbook of Perceptual Dialectology (edited by Preston, 1999a; Long \& Preston, 2002)). This study used boundary drawing on maps and brainstorming exercises to gather opinions on different varieties.

\section{The East Midlands}

Previous work (Braber, 2014) showed that the East Midlands is an interesting area linguistically, because of its shared features with northern varieties (Beal, 2008: 124; Wells, 1986: 350), as well as southern varieties (Hughes, Trudgill \& Watt, 2005: 63). Upton (2012: 258) argues that the Midlands form a transition zone between North and South and that a 
clear North/South divide cannot be made. There has been relatively little survey of the local dialects (Braber and Flynn, Forthcoming). Despite this lack of empirical evidence, anecdotally it appears that language in the East Midlands remains distinctive (both within the region and compared to other regions) and locals insist there is considerable difference, for instance, between speech in the major urban centres of Nottingham, Derby and Leicester (see for example Scollins and Titford, 2000: 5). Much of the research on language in the East Midlands comes from a historical angle, where the dialect has been studied in relation to the development of Standard English (e.g. Baugh and Cable, 2002; Fennell, 2001).

Geographically, the region also poses some unclarity, for example, what exactly is included within the East Midlands (for full details see Braber, 2014). However, the region includes a variety of types of towns and countryside, ranging from the uplands of northwest Derbyshire to the lower levels of the Lincolnshire fens in the east. For the study on which this paper is based, only Derbyshire, Leicestershire and Nottinghamshire were included. However, these counties include the three main urban centres of the region, containing the three largest cities, that is, Nottingham, Derby and Leicester, and as such the most easily recognised centres of the East Midlands.

It seems that the East Midlands do not form an important region in the mental maps of people outside the area and are seen as being "neither here nor there" (Wales, 2000: 7-8). It seems that the region does not have much cultural salience to the general public outside the East Midlands. For the North-East of England, Pearce states that outsiders' perceptions are not based on direct experience, but from representations on TV (Pearce, 2009: 164). Other studies have also examined the role of the media on representation and recognition of geographical areas (for example Bayard, 1990; Goodey, 1973; Montgomery and Beal, 2011 ; Stuart-Smith, Timmins \& Tweedie, 2007). However, the East Midlands region lacks TV representation. There are almost no soap operas or other programmes which are set in the East Midlands (which distinguishes it from many other parts of the UK) and there are few celebrities from the East Midlands who 'represent' this area (see Braber, Forthcoming). This is an important issue which could affect people in the East Midlands, because Wales states that "mental stereotypical landscapes have powerful 'real-world' implications" (Wales, 2000: 6). From this we can see that the concept of the East Midlands is a tricky one on multiple levels.

\section{Methodology}

The main goal of this study was to start the discussion of perceptual dialectology in the region and to learn about what adolescents think and know about language variation in the East Midlands and the UK more widely. It examines in detail the accents and dialects this group believes to exist in the UK and to see how well they can recognise these. There are gaps in the literature not only in the examination of linguistic varieties in the East Midlands but also in the perception and recognition of these. This paper will consider issues 
surrounding the salience of accents/dialects in the region and whether local adolescents are better are distinguishing local speech patterns than speech patterns from other regions.

I invited state secondary schools from across the East Midlands to take part in a study looking at language variation in the UK. I asked permission to attend an hour-long class with students in their final year (students aged 17-18 who were carrying out A-Levels which are the end of school exams) in order to engage with students' opinions on language variation in the UK and listen to some recorded voices (full detail on these recordings in section on dialect recognition) to try to place particular accents. Schools were not told in advance about the content of the session to try to avoid prior discussion and students influencing one another. When contacting schools in the region, I ensured that both rural and urban schools were approached. Two schools in Leicestershire, three in Derbyshire and five in Nottinghamshire agreed to participate. Some of the schools specifically asked for ALevel English classes to be involved, whereas other schools were happy for all A-Level students to take part. This meant that some schools only had small groups of students participating, while others had larger groups. In all, 327 students were involved in this study (of which 191 in Nottinghamshire, 85 in Derbyshire and 51 in Leicestershire). The locations of the schools can be seen in Figure 1 below.

Participants were given several maps of the UK and were informed that we would be carrying out a number of tasks to do with language variation in the UK and attitudes towards accents, as well as listening to some accents. Students were told there were no right or wrong answers and they should try to answer reflecting their own ideas and feelings as it was their opinions that we were interested in. Students were encouraged to carry out this work alone, without consulting others in the class as others' opinions may be different to their own. 


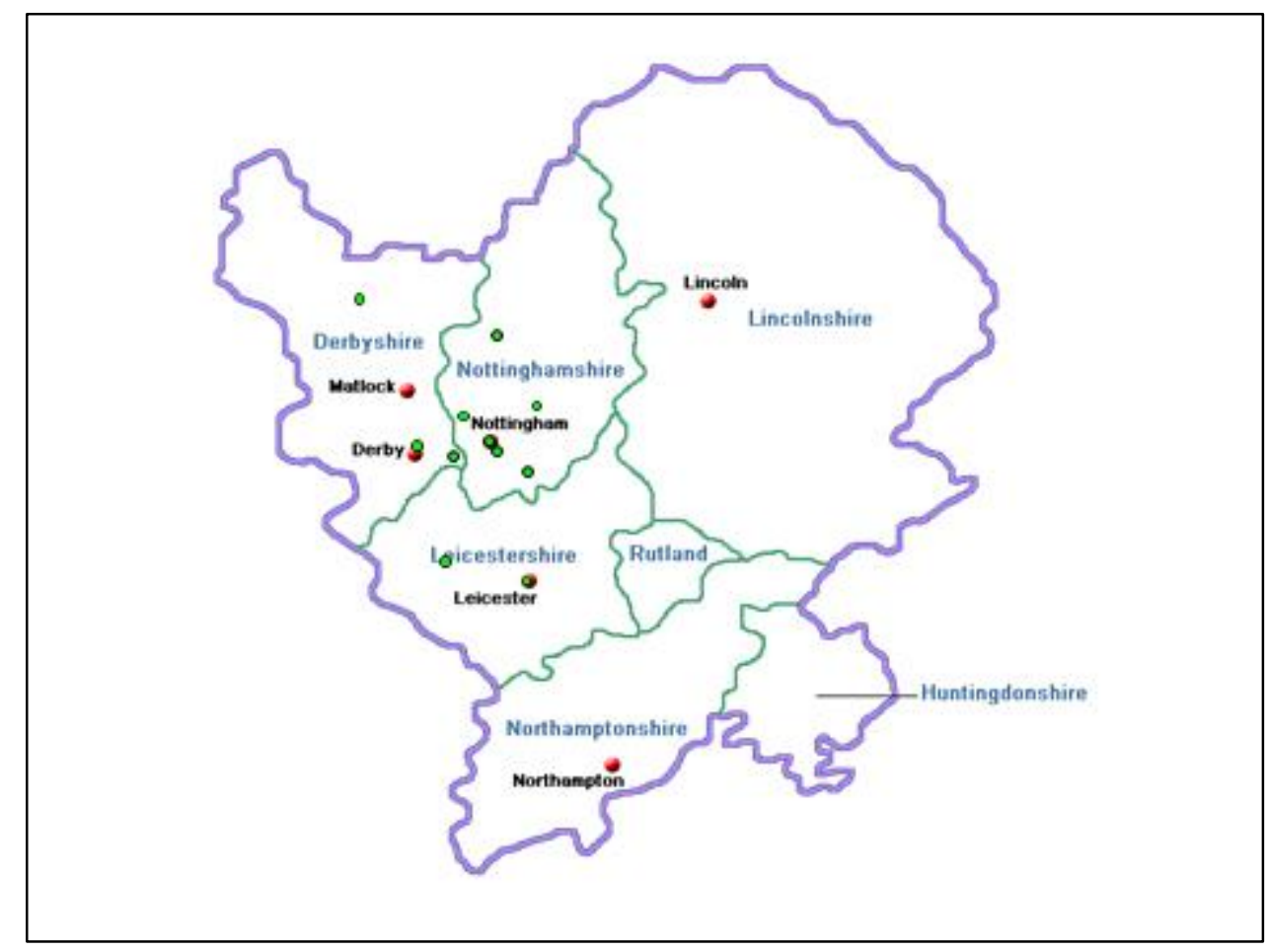

Figure 1: Locations of the school participating in the study

This paper is concerned with three tasks students were asked to carry out:

1. Draw boundaries on the map where you believe accent areas can be found and label them with comments (about pronunciation, specific words used, celebrities associated with this accent, any positive or negative attitudes and opinions);

2. Listen to 14 short extracts and put a cross on the map where you think the speakers come from.

3. Some smaller groups worked with a 'mind map' of the region where they talked about language variation in the region and were encouraged to write and talk about local differences they thought could be found in the East Midlands.

While in the school the term 'accent' was used as it was believed that most students would understand this definition, and that using the word 'dialect' could be misunderstood to only mean rural varieties of English.

Smaller groups of students took part in a brainstorming session (task 3 ) to get them talking about language variation in their area and allowing them to discuss issues raised during the tasks. As much detail as possible was elicited about regional varieties, including comments about lexical and phonetic features, stereotypes and associations (see also Kuiper, 1999: 248).

Like Preston (1996a: 40), the aim was to examine how accurate non-linguists are at recognising and placing different linguistic varieties. It could be expected that where the participants come from would affect the distinctions they make: would local participants be 
able to distinguish between different dialects of the East Midlands (in accordance with Williams et al., 1999: 345)? Which features participants are considering when making these judgements? This work allows for examination of the dialect regions that participants identify; whether they associate particular features with those varieties and how they recognise them. This would then allow us to gauge how accurate participants are at recognising local dialects.

Further considerations were influenced by the discussion by Gould and White (1974: 40) that in general we know more about the areas close to us (see also Sullivan, 2007: 7; Wells, 1982: 33), and the concept of "ignorance surfaces" (Gould and White, 1974: 120) which questions how much people know about actual areas. It examines the beliefs people may have about an area or 'knowledge' they feel they have about an area even though they may actually have very little information about it. According to Preston, examining participant knowledge is important, because it allows us to review "folk awareness" (Preston, 1996a: 45)and examine which details participants are aware of, and how they mimic varieties to examine the degree of awareness.

For the first task some students received a map on which some cities were indicated (see Figure 2) and some received blank maps. The cities on the labelled map were chosen to give a geographical spread around the UK, and included Nottingham. This spread was given to allow students to orient themselves geographically, and one city in the East Midlands was chosen to ensure they would know the location of the area if required. Some perceptual dialectologists, such as Preston (personal communication) have questioned whether having a map with cities marked on it will influence what participants do with them. So having these two maps allowed for the comparison between the two groups, to see whether different results would be given by the two different groups. When comparing the boundaries on the maps for dialect areas it appeared that the labels did not influence the outcome because the results for both groups were identical in their rank ordering (the results shown in Figure 5 did not differ for the two groups). The naming of dialect areas was counted and geographical accuracy was not judged for this task. For the identification task all students received the map with the city dots, although they were informed that the recordings did not necessarily come from these cities, but were there to guide them geographically. This confirms the findings from Montgomery (2007: 347; 2012) which suggest that giving location dots does not alter participants' naming of dialect areas. So in this paper the entire sample will be discussed as one group. 


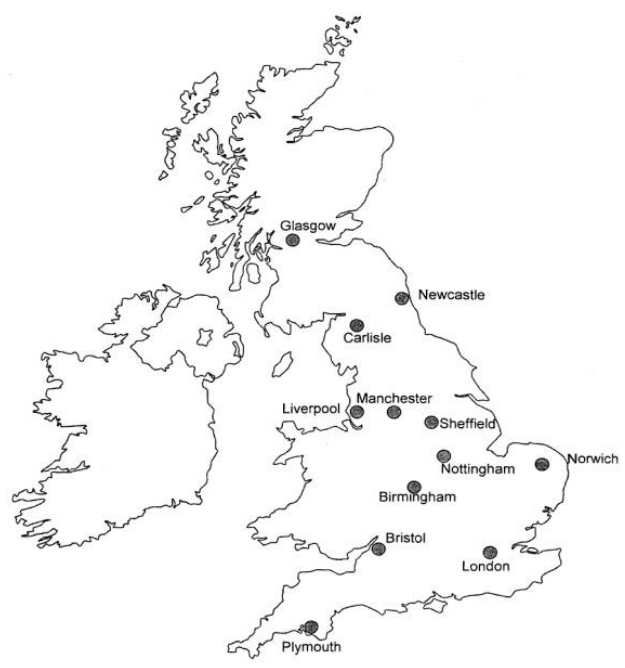

Figure 2: Map supplied to participants

\section{Findings}

\section{Dialect Divisions}

For the first task, students were asked to circle areas on the map where they thought distinct linguistic varieties were to be found, to label them with names if possible and to give any opinions they had about these varieties (what it sounded like, typical words or pronunciations, famous people who spoke with such an accent).

This task allowed examination of respondents' "actual mental map of regional speech areas" (see Preston, 1999c: 361) to see where they think varieties are different.

The responses given by these students were very variable. Some included just one or two circles (e.g. Scottish, Geordie etc, see Figure 4) whereas others drew very detailed analysis of different words used in areas and included many circles covering larger areas of the UK (see Figure 3). Due to this large amount of variation, I am only including two actual maps here for illustration purposes. 


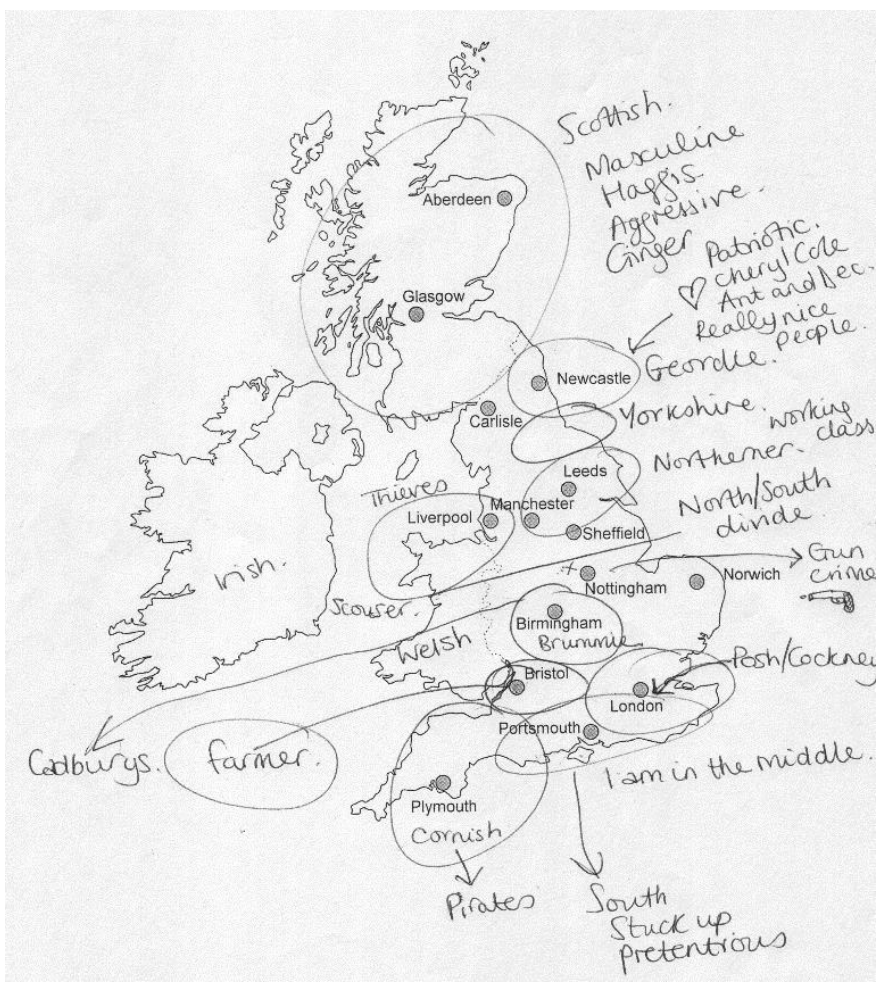

Figure 3: Accent map with more description

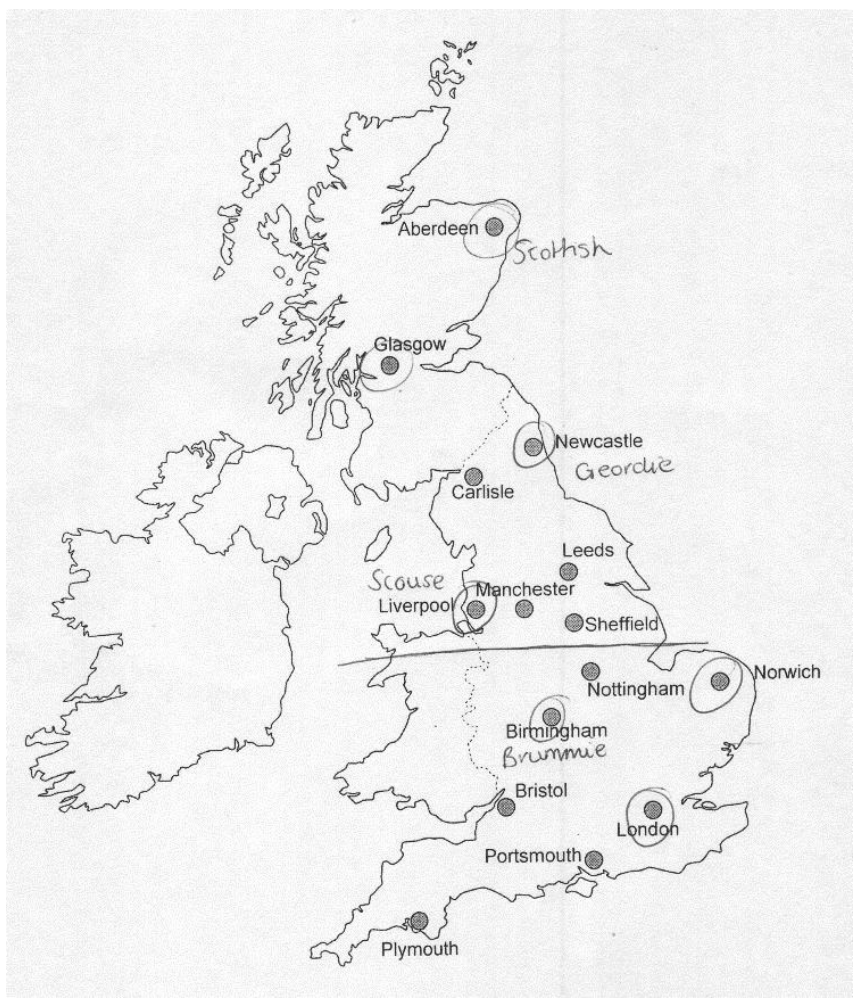

Figure 4: Accent map with little description 
As results were similar among all groups, the following section will analyse the three counties together. Interestingly, the rank ordering of dialect areas between the students with the labelled map and the blank map were almost identical (as was discussed in the methodology). I had wondered whether the map with labelled cities would encourage or bias students towards circling them, but it seems that the students who had maps without these labels included an almost identical identification of accents around the UK and did not show that the students with the maps simply circled the city names found on the map. The rank ordering of the ten most frequently named/circled dialect areas can be seen in Figure 5 below. The interpretation of such maps is not always straightforward. Some students circle city names whereas others circle larger areas. This was reflected in my analysis: where students circled a city only, this is how it was classified in my analysis and where students circled larger areas this was also signified during analysis (for example, where some students circled Sheffield and Leeds together and named it Yorkshire). Most students provided labels for areas and this was also taken into account during the analysis stage.

\begin{tabular}{|c|c|c|}
\hline Area circled/named & $\begin{array}{l}\text { Number of times } \\
\text { circled/named }\end{array}$ & $\begin{array}{l}\text { Results found by Montgomery } \\
(2007: 65)\end{array}$ \\
\hline Liverpool & $295(90 \%)$ & Geordie/Newcastle \\
\hline Birmingham & $271(83 \%)$ & Yorkshire \\
\hline Newcastle & $265(81 \%)$ & Couse/Liverpudlian \\
\hline London & $252(77 \%)$ & Manc/Manchester \\
\hline Scotland & $202(62 \%)$ & Midlands \\
\hline Manchester & $147(45 \%)$ & Cumbria \\
\hline Wales & $141(43 \%)$ & Lancashire \\
\hline Ireland & $127(39 \%)$ & \\
\hline Glasgow & $119(36 \%)$ & \\
\hline Nottingham & $84(26 \%)$ & \\
\hline
\end{tabular}

Figure 5: Rank ordering of dialect areas

Figure 5 includes results from a similar task carried out by Montgomery (2007: 65) which shows that the five dialect areas with the greatest number of recognition were Newcastle/Geordie, Yorkshire, Liverpool/Scouse, Cornish/Cornwall, Manchester. Newcastle and Liverpool were also in the top three for my participants, but Manchester appeared further down the table and Yorkshire and Cornish did not appear in the top ten. Montgomery's participants do mention Midlands in sixth position which is rarely mentioned by my participants.

These labels are taken from the students' notes and comments - so it can be seen for example, that 'Scotland' was the fifth most common 'accent' named (or circled) by students, but a term like 'Glasgow' or 'Glaswegian' came ninth - this was due to the fact that some students just put a circle around the whole of Scotland, while others tried to make distinctions between different areas of Scotland (and some students did both). The four 
most common accents (Liverpool, Birmingham, Newcastle and London) had relatively similar scores, and all were recognised by over 250 students (out of 327 ) as being distinctive accents in the UK. After that, the numbers dropped rapidly - Scotland was still seen by just over 200 students as being distinctive, but this declined to around 140 for Manchester and Wales, with Ireland and Glasgow coming behind this. The tenth most common accent named was Nottingham, however only 84 of the students had named or circled this variety.

I was also interested in the ways students labelled their own areas, and which areas were left blank. Nottingham was recognised as a distinctive accent by students in all three counties (although it is important to remember that Nottinghamshire students made up a larger group in this sample). But even the students from Derbyshire and Leicestershire very rarely included their own areas as having an accent. Only 8 participants labelled Leicester/Leicestershire as having a distinctive accent (and all of these students were from the schools in Leicestershire) and a further 3 had labelled Derby/Derbyshire (again all from schools in that county). There were also 11 students who marked a 'Midlands' accent on the map, which does not distinguish a specific area in the Midlands (such as 'East' or 'West'). Interestingly, one of the voice samples in the third task below was from the West Midlands (just outside Birmingham) and the students all very strongly felt that this speaker used a different accent to their own.

So it seems from this task that the East Midlands accent is not seen as being an obvious candidate for showing regional variation. This may be due to the age of the cohort as they may not be aware of having an accent themselves, but as stated previously, these students are aware of local and regional variation due to extensive contact with media which more frequently contains non-standard varieties. It can also suggest that the East Midlands may be an area which lacks cultural saliency and is therefore not immediately recognised as an individual area, which will be discussed later. The next task will examine how well these participants can recognise accents, including those used in their own areas.

\section{Dialect Recognition}

In this second task students were asked to listen to 14 extracts and to put a cross on the map where they thought the speaker was from - this included locations from around the UK (including a Northern Irish, Scottish and Welsh accent, as well as one from Plymouth, Ashford (Kent), London, Newcastle, Birmingham, Burnley, Withernsea (East Yorkshire) and Liverpool) and three 'local' dialects (Nottingham, Leicester and Derby). These locations can be found on figure 6 . These maps all had city dots on them but students were told that these were geographical guidance and did not necessarily mean that the voices they heard would be from these areas. Only 303 participants took part in this task due to equipment failure in one Nottingham school. For ease of viewing, the centre of each cross is represented by a dot on the map to allow for a greater number of responses to be seen accurately. 
The voices the participants heard were all female, working-class and young to middle-aged. Most of the recordings come from the British Library archives (these can be accessed online: http:// sounds.bl.uk/Accents-and-dialects/Millenium-memory-bank), although the voices from Nottingham and Derby had to be recorded additionally as there were no voices on the British Library sound archives which matched the other voices and did not state where the listener was from. These recordings were examples of natural speech with the women talking about neutral topics. All efforts were made to ensure that the participants were representative of the areas they come from and they all sounded like "natural speakers" (Bayard, 1990: 76). Bayard et al. comment that all voice recordings are potentially problematic and that "the search for a perfect stimulus tape is perhaps futile" (Bayard, Weatherall, Gallois \& Pittam, 2001: 24). Other studies comment that speakers should be "suitably authentic-sounding" (Ball, 1983: 166) and this was achieved for these samples.

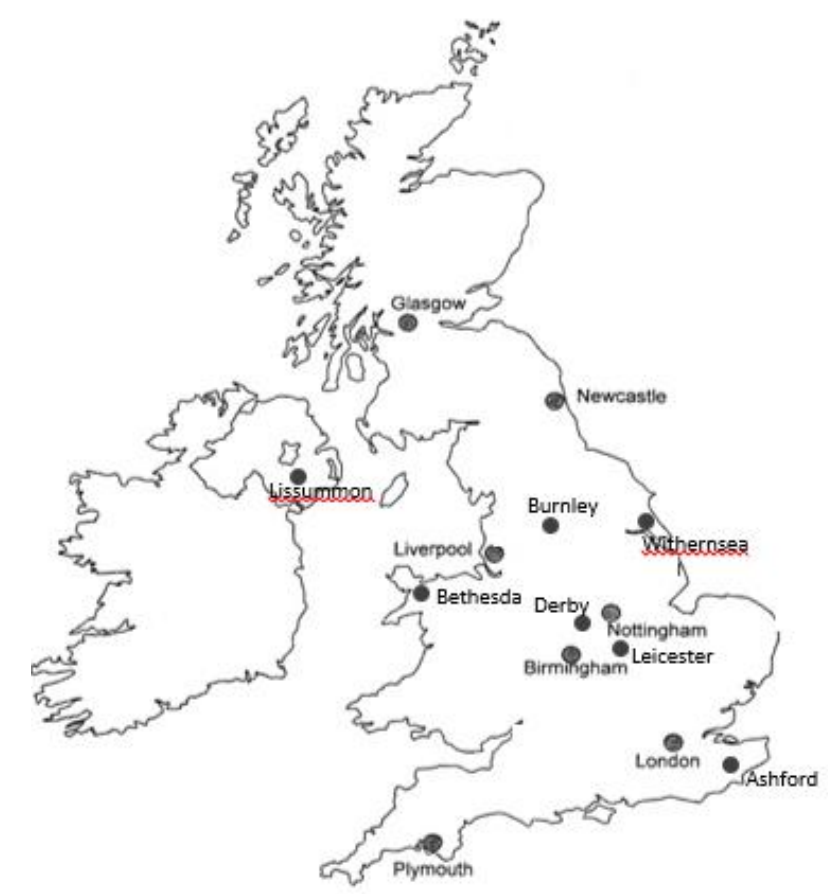

Figure 6: Locations of voice recordings

This study is particularly interested in how well the students were able to recognise 'local' voices and whether they would be better at this than voices which come from further away. From the results it seems that the dialects commonly named in the previous task were also accurately labelled in this task (particularly Liverpool; Newcastle and Birmingham and Wales), which may be those with the highest sense of cultural salience, i.e. they are well represented in the media. However, London, Glasgow and Lissummon (Northern Ireland) as well as the local dialects were generally labelled less accurately. 
For example, the most frequently named language variety in the previous task was that of Liverpool and this was very accurately recognised by these students (see figure 7 below). We can see the clear clustering of dots around the Liverpool centre and surrounding area (stretching towards Greater Manchester). There are some dots which are wide off the mark, including a few near London and Birmingham but the overall recognition is very high. The map for Newcastle was similarly accurate to this one.

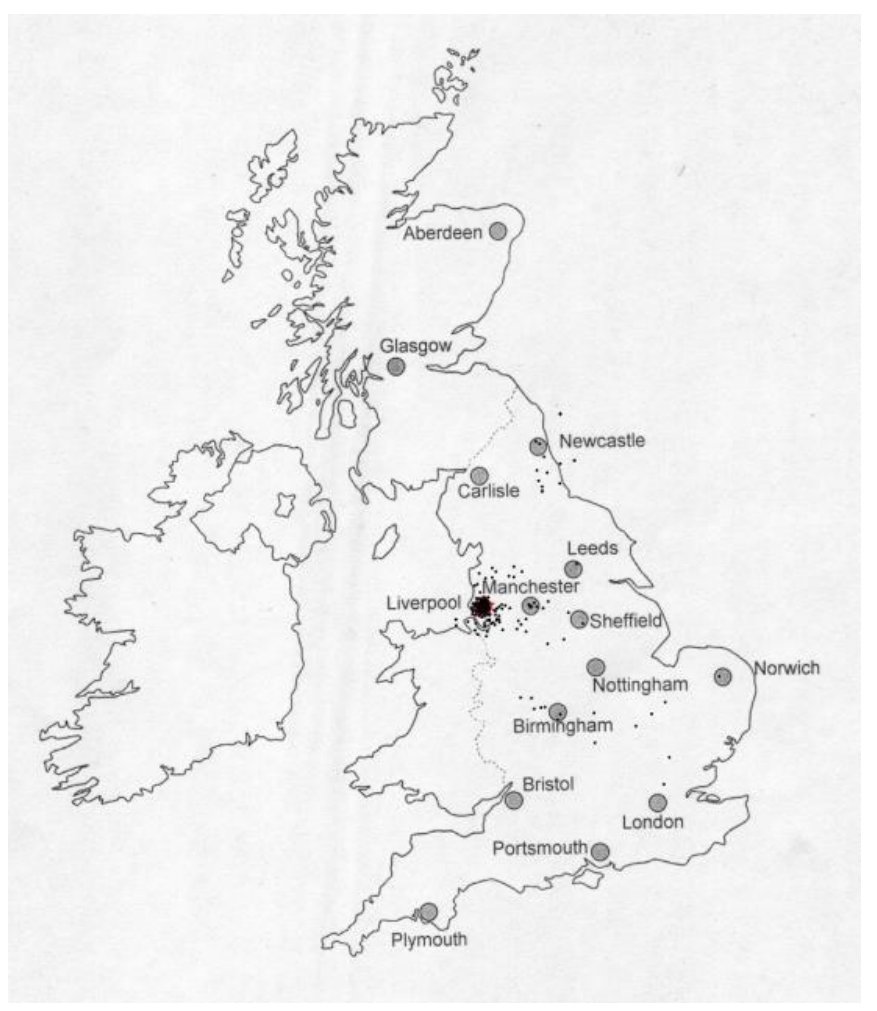

Figure 7: Accent Recognition of Liverpool

Unlike Williams et al. (1999) and Wells (1982) we discovered that participants were unable to situate local voices accurately. Not only were participants not able to distinguish different dialects within the East Midlands (which many state in the mind maps task as being distinctive), but they are not able to recognise that the voices from Derby, Nottingham and Leicester are from the East Midlands. Instead they place them all around the country, with locations being placed as far north as Manchester and Leeds, and as far south as Plymouth and London. For illustration, the voice recognition task with the Nottingham voice is illustrated in Figure 8 below. We can see from this map that it is not the case that these students think the Nottingham voice is from a particular region as the spread ranges around England.

These results were then broken down to examine whether participants would be more accurate at recognising their 'own' dialect (for example whether the Nottinghamshire 
students would be better at recognising the voice from Nottingham than the Derbyshire and Leicestershire students). It was found that students were no better at recognising their own dialect than any of the others. Current research being carried out by the author is examining the distinctiveness between these East Midlands dialects in order to investigate to what extent the varieties of these East Midlands cities differ.

From this task we can see that some accents may be harder to recognise for these participants and local varieties are included in this. The final task will involve a selection of these students carrying out more detailed tasks looking at language variation in the East Midlands.

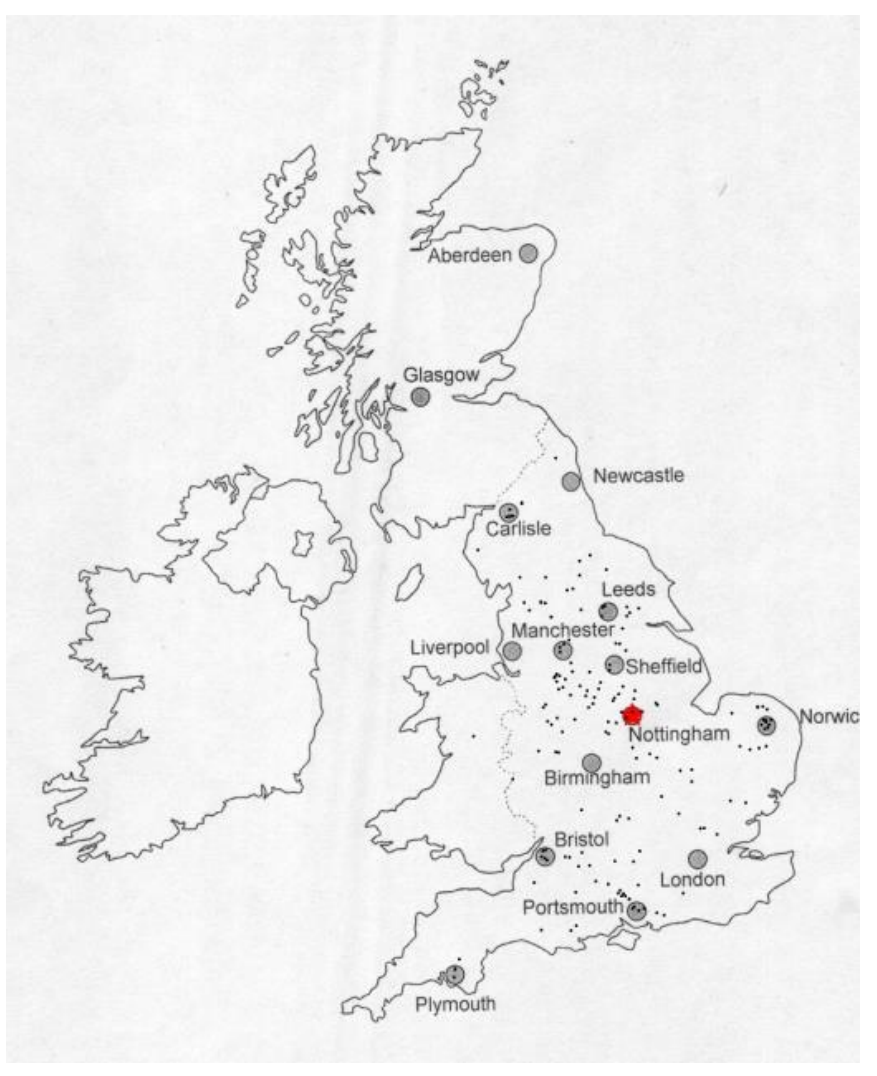

Figure 8: Accent recognition of Nottingham

\section{Mind Maps}

The third and final activity was only carried out in two schools in each county (with a total of 12 mind maps overall, this is due to some class sizes being larger than others and having more mind maps in one class). The students in these schools were divided into smaller groups and were given a map of the East Midlands and a set of felt-tip pens. They were asked to talk about (and write down) language in their local and surrounding areas. Students were asked to think about where language started sounding different, how it was different, and give examples of words and/or pronunciations of different accents in the region. These conversations were not recorded as by their very nature would have been almost impossible to analyse in this way, but students were encouraged to make extensive notes on the map 
and these were discussed in great detail alongside some field notes made by the researcher. Students were also encouraged to feed back their discussions to others within the group to examine whether students agreed or disagreed on the issues raised.

I had expected that some of the students would feel uncertain about expressing such opinions during some of the earlier tasks, and thought that students might be more willing to discuss local varieties on a more personal level during this task. This turned out to be a very rich way of finding out about perceptual dialectology and the task generated animated discussions, much of which centred on ideas about the 'ugliness' and 'negativity' surrounding their local accents (see Figure 9 for an example of one of these maps).

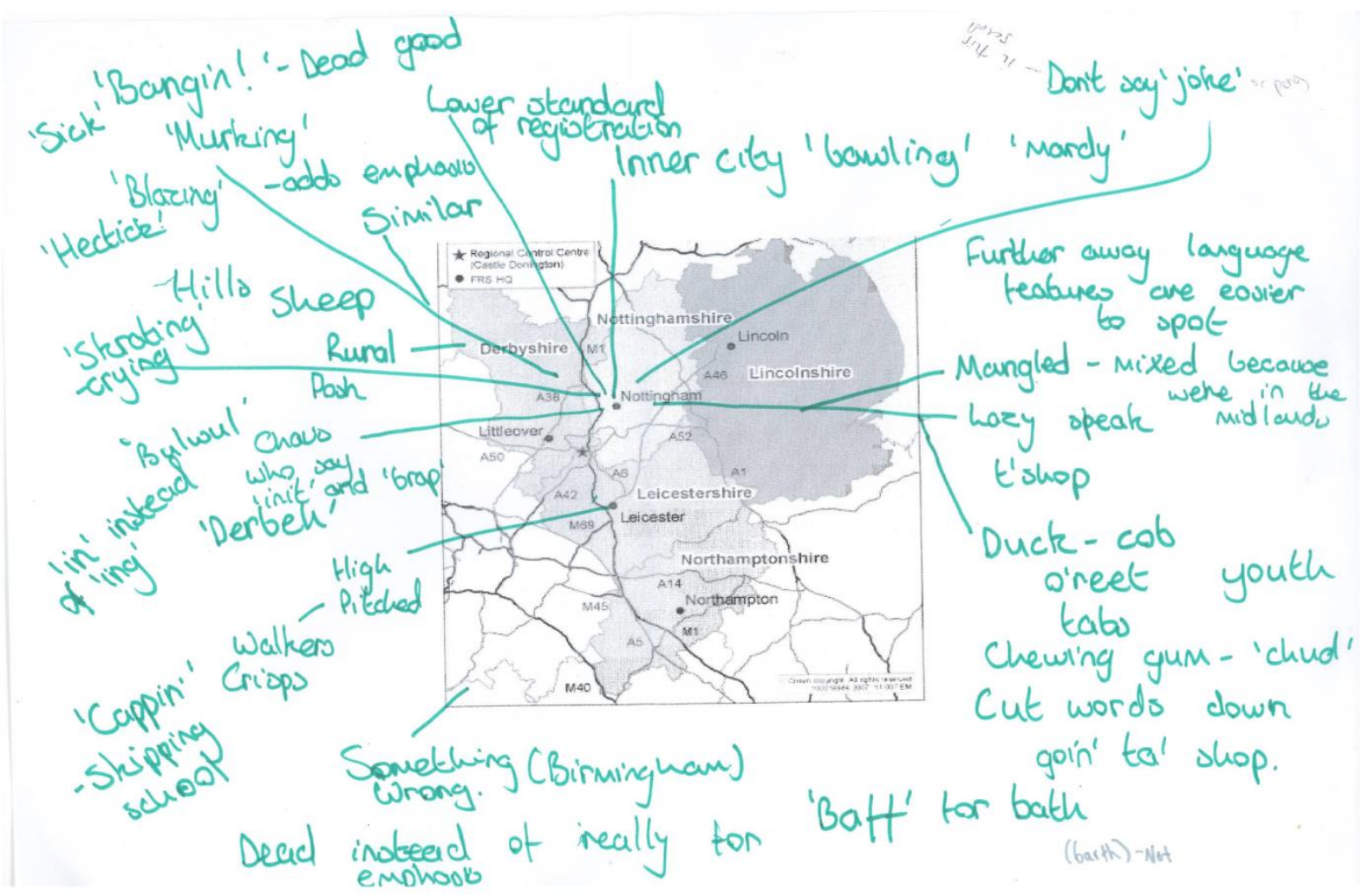

Figure 9: Example of Mind Map

As was to be expected in such an exercise, there were certain issues which were constant for many of the participants and some which differed among the groups. Language variation within the East Midlands was a contentious issue. Some students commented that there was no variation in the East Midlands but the majority of students agreed that there were differences within the East Midlands. Students from around the East Midlands thought that Derbyshire was more 'rural' and therefore sounded more 'country' than the other counties. Others commented that Nottingham and Leicester were heavily influenced by being multicultural and were also as more 'urban' and therefore more 'rough'. One interesting comment made (and then discussed further within the group) was that someone from London would not be able to tell the difference between someone from Nottingham, Derby and Leicester. This implies that people from the East Midlands would be able to do so. However, as we can 
see from the previous task this is certainly not the case for the majority of these participants.

As regards typical features of the East Midlands, these students were very insightful and commented on features which I think are typical features of the East Midlands including phonological, lexical and morpho-syntactic variation. Some of these were lexical items (particularly 'cob' for bread roll, 'mardy' for grumpy, 'mi duck' as a term of endearment, 'reet' for right, 'sen' for self as well as other items which may be more typical of youth language throughout the UK, such as 'peng' for good/attractive and 'innit' for isn't it). They also mentioned definite article reduction and reduction of prepositions. There were several phonetic features which were also frequently mentioned as being typical of the East Midlands, or particular areas within the East Midlands, such as the short /a/ in BATH, the non-split FOOT/STRUT in words like 'cup', the happY vowel approaching the DRESS vowel, hdropping, $\mathrm{t}$-glottalisation, and the distinctive final shwa-vowel in Leicester being pronounced as 'Lestah' or 'Lestoh'. There is much valuable information about these mind maps dealing with regional variation which is currently being analysed and will form the basis of future publications.

Much of the discussion centred on the perceived ugliness of the dialect. Students mentioned that it was lazy, slurred, chavvy ('chav' is a derogatory term used to describe loud and brash working-class youths), boring, rough, not proper, nothing unique, fast and some said that they did not like it or were trying to get rid of it. These characterisations were frequent and widespread. Only one or two students said that it was relatively easy to understand and one student that it was friendly. This raises questions for future research examining why there should be so much negativity surrounding East Midlands dialects held by these young people, which is the focus of a forthcoming research article (Braber, Forthcoming).

\section{Discussion}

The students are unlikely to name the East Midlands when naming dialect areas around the UK. Furthermore, they are also inaccurate when it comes to labelling the East Midlands voices in the dialect recognition tasks. Why do the East Midlands rarely feature as one of the dialects named by students? Previous studies have shown that there are trends towards selfidentification (Preston, 1989: 118) - so do these empty spaces in the East Midlands reflect something else? Long (1999a: 186) found that many participants in his study did not treat their home area as having dialect boundaries. Is the East Midlands an area which has no characteristic linguistic features or no popular cultural notoriety (Preston, 1989: 121)? It is certainly not the first statement as the students feel there are differences within the East Midlands and they express this in the mind map task, but perhaps the second statement could be important? Inoue (1999: 164) and Long (1999a: 186) comment that previous studies have shown that people are often more sensitive to dialectal differences near their 
birthplaces (the proximity effect). Kerswill and Williams suggest that it could be to do with the influence of the broadcast media (Kerswill and Williams, 2002: 200). The effect has been supported by other studies which have shown that participants were only able to identify dialects that are often heard in the media (see Inoue, 1999: 162) or those that are the focus of a particular activity, such as football (Wales, 2000: 14-5). The East Midlands may not have much cultural salience and this could result in students making errors in recognising and categorising the recorded voices. From some of the maps we can see that celebrities from a region may help with recognition and it seems that there are few obvious local celebrities from the East Midlands (this lack of cultural salience is discussed further in Braber, Forthcoming). We may also need to consider whether own community recognition will be better among those with strong local ties and consider the geographical mobility of individual participants.

Another aspect of the issue of the inability to label local varieties is brought out by students rating them negatively when they discuss the mind maps. This can be linked to the concepts of 'claiming' and 'denial' where voices are not recognised as local if they are not perceived positively (see Long, 1999b: 220; Montgomery and Beal, 2011: 138; Williams et al., 1999: 356). Only two students make positive comments about the local varieties (friendly and easy to understand), a few comment that their local variety is relatively neutral and the rest are negative, classifying it as common, plain, boring, slang, rough, horrible, nothing unique, not proper, chavvy, disgusting chavs, lazy, and that they are trying to get rid of it.

We may also need to consider the individual speech samples - the recordings were used as it was believed that they represented 'authentic' and 'local' speech norms - perhaps some samples contain features (whether phonological or other) that could mislead the participants into recognising, or not recognising particular varieties. This phenomenon is discussed in the Williams et al. (1999: 352) study, which asserted that certain content cues could lead to faulty misidentification, although they do state that these only account for some of the misrecognition and that other attitudinal factors are also important. It is possible that this age group is less accurate at recognising accents and dialects (see for example Diercks, 2002: 58), but other studies have shown young participants are good at recognising own accents, (see Kerswill and Williams' discussion of the Williams et al. study, 2002: 174).

Kerswill and Williams discuss the fact that the recognition process is mediated by other factors such as life experience, the absolute linguistic difference between the different samples in the recognition task and the perceived social attractiveness of the speaker (Kerswill and Williams, 2002, 176) so these factors could have influenced these participants. Diercks (2002: 51-2) mentions the fact that dialect speakers tend to circumscribe the area in which they speak their own dialect and cut themselves off from dialects spoken in the surrounding areas creating a "linguistic homeland" and that the function of dialects is a 
"socio-psychological identification of one's own territory" (Diercks, 2002: 51-52 citing Greverus, 1972). It is not clear if this is the case for these participants - very few of them have problems with deciding on the position of the North/South divide (although these are very variable) but have problems deciding on their own identity (see Braber, 2014).

Finally, the students in these sample groups have opinions on differences in their local dialects. A few state that there are similarities within the East Midlands, but many comment on the differences between Leicester, Nottingham and Derby, while others say that different parts of Nottingham have different accents. One student believed that it was due to 'sociolect' rather than dialect! As expected, the students find it very hard to explain why these varieties are different.

\section{Conclusion}

It seems clear that students are unlikely to name or recognise local voices and treat them negatively in discussion. Follow up research could include using Montgomery's starburst method (see for example 2012) to quantify the accuracy of the placements in the dialect recognition tasks. This would establish whether there are particular trends in the misidentification of these local accents or whether they are more random. Initial examination suggests that the misplacement is random, but further work needs to be carried out.

Future work could involve carrying out further research with adults to discover how accurately they can identify local voices. Furthermore, examining media influence could be an interesting issue for future work. Some participants seemed to suggest some sort of media influence during the tasks, particularly with London accents (comments about EastEnders (a soap opera set in the East End of London) and specific characters from such programmes appeared on the maps). It may be important to look at "not only what speech community members know about varieties but also how they construct this knowledge and how they use it creatively to reflect and refine their group priorities and memberships." (Williams et al., 1999: 358). More research is needed to examine what such mental maps can tell us about the perception of language and particularly why there seem to be so many negative attitudes among these young people surrounding the East Midlands accents.

\section{References}

Ball, P. 1983. 'Stereotypes of Anglo-Saxon and non-Anglo-Saxon accents: Some exploratory Australian studies with the matched guise technique'. Language Sciences, 5, 163-183. Baugh, A.C. \& Cable, T. 2013 . A history of the English language. London: Routledge. Bayard, D. 1990. "God help us if we all sound like this': attitudes to New Zealand and other English accents'. In A. Bell and J. Holmes (eds.) New Zealand ways of speaking English. Clevedon: Multilingual Matters, pp. 67-96. 
Bayard, D., Weatherall, A., Gallois, C. \& Pittam, J. 2001. 'Pax Americana? Accent attitudinal evaluations in New Zealand, Australia and America'. Journal of Sociolinguistics, 5(1), 22-49. Beal, J. 2008. 'English dialects in the North of England: phonology'. In B. Kortmann and C. Upton (eds.) Varieties of English. The British Isles. Berlin: Mouton de Gruyter, pp. 122-144. Braber, N. (2014). 'The Concept of Identity in the East Midlands'. English Today 30(2), 3-10. Braber, N. (Forthcoming). 'Dialect Perception and Identification in Nottingham'. In: J. Cramer and C. Montgomery (eds.) Cityscapes and Perceptual Dialectology: Global perspectives on non-linguists' knowledge of the dialect landscape. Berlin: Mouton de Gruyter.

Braber, N. \& Flynn, N. (Forthcoming). 'The East Midlands: Nottingham'. In R. Hickey (ed.) Researching Northern Englishes. Amsterdam: John Benjamins.

Clopper, C.G. \& Pisoni, D.B. 2004. 'Some acoustic cues for the perceptual categorization of American English regional dialects'. Journal of Phonetics, 32, 111-140.

Diercks, W. 2002. 'Mental Maps'. In D. Long and D. Preston (eds.) The Handbook of Perceptual Dialectology, volume 2. Philadelphia: Benjamins, pp. 51-70.

Fennell, B. 2001 . A history of English. A sociolinguistic approach. Oxford: Blackwell. Goodey, B. 1973. Perception of the environment. University of Birmingham: Centre for Urban and Regional Studies.

Gould, P. \& White, R. 1974. Mental Maps. London: Penguin. Hughes, A., Trudgill, P. \& Watt, D. 2012. English accents and dialects. London: Hodder Arnold.

Inoue, F. 1999. 'Subjective Dialect Division in Great Britain'. In D. Preston (ed.) The Handbook of Perceptual Dialectology, volume 1. Philadelphia: Benjamins, pp. 161-176. Kerswill, P. \& Williams, A. 2002. 'Dialect Recognition and Speech Community Focusing in New and Old Towns in England'. In D. Long and D. Preston (eds.) The Handbook of Perceptual Dialectology, volume 2. Philadelphia: Benjamins, pp. 173-204.

Kuiper, L. 1999. 'Variation and the Norm. Parisian Perceptions of Regional French'. In D. Preston (ed.) The Handbook of Perceptual Dialectology, volume 1. Philadelphia: Benjamins, pp. 243-262.

Long, D. 1999a. 'Geographical Perceptions of Japanese Dialect Regions'. In D. Preston (ed.) The Handbook of Perceptual Dialectology, volume 1. Philadelphia: Benjamins, pp. 177-198. Long, D. 1999b. 'Mapping Nonlinguists' Evaluations of Japanese Language Variation'. In D. Preston (ed.) The Handbook of Perceptual Dialectology, volume 1. Philadelphia: Benjamins, pp. 199-226.

Long, D. \& Preston, D (eds.) 2002. The Handbook of Perceptual Dialectology, volume 2. Philadelphia: Benjamins.

Montgomery, C. 2007. 'Northern English Dialects: A Perceptual Approach'. Unpublished PhD Thesis. Sheffield: The University of Sheffield.

Montgomery, C. 2012. Perceptual prominence of city-based dialects in the city. Paper presented at Sociolinguistics Symposium 19, held in Berlin, August 21-24, 2012. 
Montgomery, C. \& Beal, J. 2011 . 'Perceptual Dialectology'. In W. Maguire and A. MacMahon (eds.) Analysing Variation and Change. Cambridge: CUP, pp. 121-148.

Pearce, M. 2009. 'A Perceptual Dialect Map of North East England'. Journal of English

Linguistics, 39(3), 162-192.

Preston, D. 1989. Perceptual Dialectology. Dordrecht: Foris.

Preston, D. 1996a. 'Whaddayaknow? The modes of folk linguistic awareness'. Language

Awareness, 5, 40-73.

Preston, D. 1996b. 'Where the worst English is Spoken'. In E. Schneider (ed.) Focus on the USA. Amsterdam: Benjamins, pp. 297-360.

Preston, D. (ed.) 1999a. The Handbook of Perceptual Dialectology. Philadelphia: Benjamins.

Preston, D. 1999b. 'Introduction'. In D. Preston (ed.) The Handbook of Perceptual

Dialectology, volume 1. Philadelphia: Benjamins, xxiii-xl.

Preston, D. 1999c. 'A Language Attitude Approach to the Perception of Regional Variety'. In:

D. Preston (ed.) The Handbook of Perceptual Dialectology, volume 1. Philadelphia:

Benjamins, pp. 359-373.

Preston, D. 2002. 'Language with an Attitude'. In J.K. Chambers, P. Trudgill \& N. Schilling-

Estes (eds.) The Handbook of Language Variation and Change. Oxford: Blackwell, pp. 40-66.

Scollins, R. \& Titford, J. 2000. Ey up mi duck! Dialect of Derbyshire and the East Midlands.

Newbury: Countryside Books.

Stuart-Smith, J., Timmins, C. \& Tweedie, F. 2007. “Talkin' Jockney'? Variation and change in Glaswegian accent'. Journal of Sociolinguistics, 11 (2), 221-260.

Sullivan, C. 2007. 'Towards an Integrated Perceptual Sociolinguistics'. Online at

http://www.swarthmore.edu/SocSci/Linguistics/Papers/2007/sullivan_colin.pdf Accessed April 2013.

Upton, C. 2012. 'The Importance of Being Janus'. In M. Markus, Y. Iyeiri, R. Heuberger and E. Chamson (eds.) Middle and Modern English Corpus Linguistics. Amsterdam: John Benjamins, pp. 257-268.

Wales, K. 2000. North and South: An English linguistic divide? English Today, 16(1), 4-15. Wells, J.C. 1982. Accents of English 1. An Introduction. Cambridge: Cambridge University Press.

Wells, J.C. 1986. Accents of English 2. The British Is/es. Cambridge: Cambridge University Press.

Williams, A., Garrett, P. \& Coupland, N. 1999. 'Dialect Recognition'. In D. Preston (ed.) The Handbook of Perceptual Dialectology, volume 1. Philadelphia: Benjamins, pp. 345-358. 
